\title{
Synthesis of Recoded Bacterial Genomes toward Bespoke Biocatalysis
}

\author{
Nikel, Pablo Ivan
}

Published in:

Trends in Biotechnology

Link to article, DOI:

10.1016/j.tibtech.2019.07.001

Publication date:

2019

Document Version

Early version, also known as pre-print

Link back to DTU Orbit

Citation (APA):

Nikel, P. I. (2019). Synthesis of Recoded Bacterial Genomes toward Bespoke Biocatalysis. Trends in Biotechnology, 37(10), 1036-1038. https://doi.org/10.1016/j.tibtech.2019.07.001

\section{General rights}

Copyright and moral rights for the publications made accessible in the public portal are retained by the authors and/or other copyright owners and it is a condition of accessing publications that users recognise and abide by the legal requirements associated with these rights.

- Users may download and print one copy of any publication from the public portal for the purpose of private study or research.

- You may not further distribute the material or use it for any profit-making activity or commercial gain

- You may freely distribute the URL identifying the publication in the public portal

If you believe that this document breaches copyright please contact us providing details, and we will remove access to the work immediately and investigate your claim. 


\section{Spotlight}

\section{Synthesis of Recoded Bacterial Genomes toward Bespoke Biocatalysis}

\author{
Pablo I. Nikel $\mathbb{1}^{1, *, @}$
}

Ongoing efforts in synthetic biology aim at constructing (micro)organisms with (pre)defined properties. A recent breakthrough is the chemical synthesis of a recoded Escherichia coli genome by Fredens et al. (Nature, 2019). Besides the conceptual and technological tour de force, the consequences of this unprecedented effort for whole-cell biocatalysis are multifold.

Continuous technological advances in DNA synthesis have realized some of the most ambitious objectives of synthetic biology: the creation of organisms carrying synthetic genomes [1,2]. Fredens and colleagues [3] adopted a convergent approach to de novo synthesis of genomic DNA to replace the chromosome of reduced-genome Escherichia coli strain MDS42. In addition, the synthetic genome of $E$. coli Syn61 was recoded, and two sense codons (TCG and TCA, encoding a serine residue) and a stop codon (TAG, found 321 times in the wild-type $E$. coli genome) were removed, resulting in a synthetic bacterium that relies on 61 codons (59 amino-acid-encoding codons, two stop codons) for protein synthesis. This massive engineering effort also required substantial refactoring of convergent and overlapping open reading frames, with the entire chromosome divided in 100-kb DNA fragments, which were synthesized de novo and then assembled in yeast to facilitate the process. Notably, the rate of nonprogrammed mutations during the process was only $2 \times 10^{-4}$ per target codon, significantly below the rate of unintended mutations reported in other synthetic genomics programs.

The first question that any microbial physiologist would ask is how the synthetic E. coli strain performs in the laboratory environment. Syn61 fared well across different growth conditions when compared with E. coli MDS42, although the specific growth rates were lower in all the media tested and the individual cells were slightly longer than the parental bacterium. Moreover, no major differences were detected in the composition of the total proteome of the synthetic E. coli. From a fundamental perspective, these observations led to the question of (conditional) gene essentiality, and point to our limited knowledge of the basic principles governing the architecture of the 'paleome' [4] - limitations also highlighted by other ongoing genome engineering efforts, such as the construction of the streamlined Mycoplasma mycoides strain JCVI-Syn3.0 [5]. Unknowns set aside, the possibilities of a synthetic, recoded microorganism for bioproduction are fascinating.

Over the past few decades, metabolic engineering has enabled the development of microbial strains for the production of a wide variety of chemicals and materials. A turning point in this endeavor has been the inception of systems metabolic engineering, which integrates tools and strategies of systems biology, synthetic biology, and evolutionary engineering with traditional metabolic engineering [6]. Indeed, continuous improvements in this interdisciplinary strategy have led to the development of a number of industrially competitive engineered strains. Yet, the number and chemical nature of the compounds that can be accessed through these approaches is somewhat limited by the extant biochemistry of the microbial host. While de novo DNA synthesis offers the possibility of recoding bacterial genomes [3], a closely related approach could soon lead to recoded biochemistry in synthetic microorganisms (Figure 1). As the ability to encode novel functions in synthetic DNA keeps increasing (for instance, by reassigning codons to non-natural amino acids and novel proteins thereof), the catalytic properties of engineered bacterial hosts could be significantly expanded in the not-so-distant future. Against this background, the extant biochemistry of the cells, based on a limited number of chemical elements of the periodic table, could be broadened into a neometabolism that incorporates new-to-biology chemical bonds [7]. Such a rational, bottom-up recoding of Life, encompassing not only genetic material (hardware) but also the software of the cell, will have an enormous impact on biobased production by enabling the synthesis of compounds that so far strictly belong to the realm of traditional chemistry.

Synthetic genomics could be also applied to other (micro)organisms beyond E. coli, the traditional workhorse of bioproduction, for biocatalysis applications. Although other synthetic organisms are currently in the pipeline (notably Saccharomyces cerevisiae [8], soon to become the first synthetic eukaryote), the adoption of alternative hosts for synthetic genomics could lead to additional interesting developments. For instance, some bacteria are naturally endowed with physiological features that are attractive for bioproduction, such as stress-resistant Pseudomonas putida or fast-growing Vibrio natriegens [9]. Recoding their (synthetic) genomes could add extra benefits to such built-in properties, multiplying the values of these hosts as biotechnological platforms, but also challenging the concept of species (for instance, creating a completely synthetic organism that runs a neometabolism centered on silicon or halogens). This type of approach will help to unveil and reprogram the complex wiring and multidimensional regulation of genotype-tophenotype relationships. Several longstanding questions will be tackled afresh, 


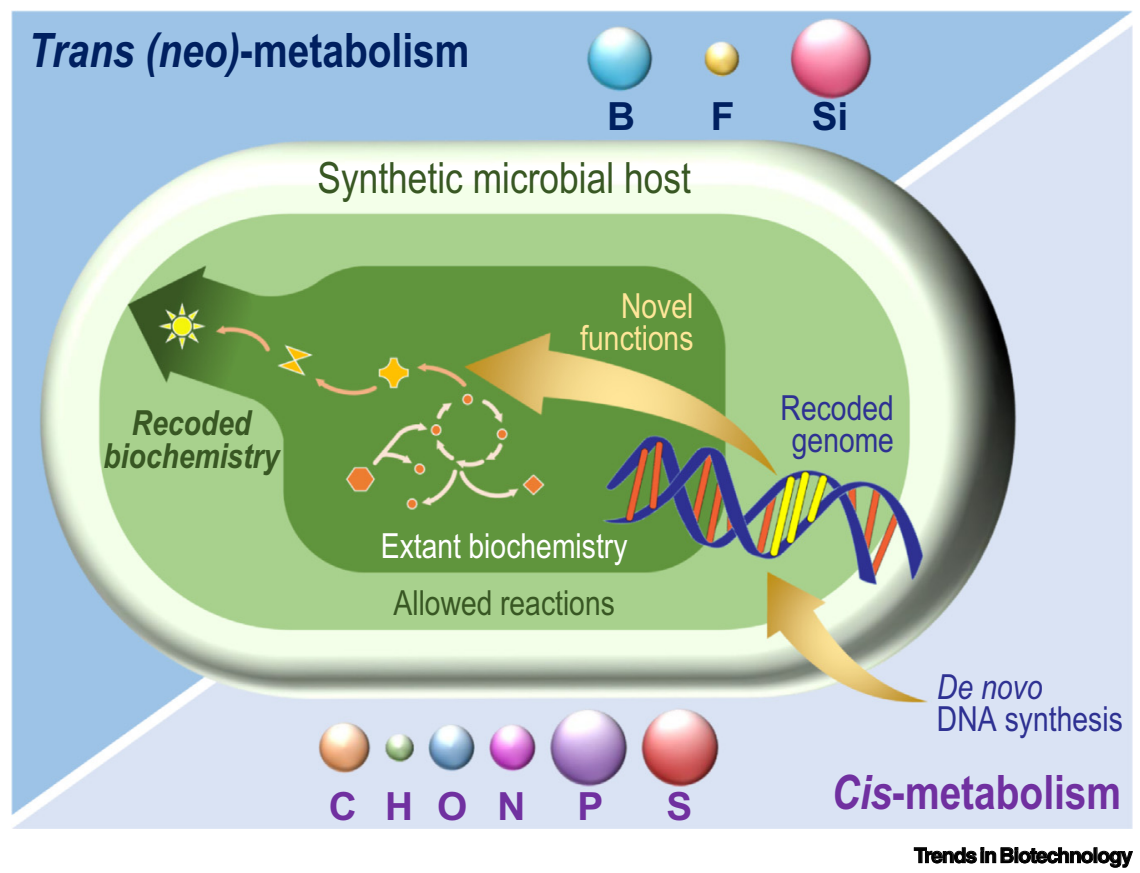

Figure 1. Synthetic, Recoded Genomes Will Empower Efficient Bioproduction beyond the Customary Products of Bacterial Metabolism. De novo synthesis of genomes and their implantation in synthetic organisms will allow for the introduction of complex, novel bioreactions, expanding the known landscape of biochemical transformations in the cell into what could be termed recoded biochemistry. These engineering operations will in turn enable the exploration (and exploitation) of neometabolism that incorporates chemical elements previously alien to the extant biochemistry of the bacterial host.

for instance, understanding (and building) a minimal metabolism [10].

While the ongoing projects of synthetic genomics herald a bright future for bespoke bioproduction, several standing questions will have to be addressed. Some of these questions are currently a matter of lively discussions in the synthetic biology arena, such as the role of evolution in the performance of synthetic organisms or how (and if) a bioprocess based on such organisms could be scaled up [11]. These emerging approaches will also shine a new light on safety assessment and regulation of genome-edited products [12], since the properties of whole-cell catalysts (including those that should be avoided) will be rendered amenable to tailoring. One way or the other, the work by Fredens and colleagues constitutes a formidable stepping stone toward the understanding and (re)programming of the core properties of the cell - the consequences of which will start to become evident in the near future, particularly in the domain of bioproduction.

\section{Acknowledgments}

The work in the author's laboratory is partially supported by The Novo Nordisk Foundation (NNF10CC1016517 and NNF180C0034818), the European Union's Horizon2020 Research and Innovation Programme under grant agreement No. 814418 (SinFonia), and the Danish Council for Independent Research (SWEET, DFF-Research Project 8021-00039B).

${ }^{1}$ The Novo Nordisk Foundation Center for Biosustainability, Technical University of Denmark, Kongens Lyngby, Denmark

\section{${ }^{*}$ Correspondence:}

pabnik@biosustain.dtu.dk (P.I. Nikel).

${ }^{\circledR}$ Twitter: @PabloINik (P.I. Nikel)

https://doi.org/10.1016/..tibtech.2019.07.001

(c) 2019 Elsevier Ltd. All rights reserved.

References

1. Casini, A. et al. (2015) Bricks and blueprints: methods and standards for DNA assembly. Nat. Rev. Mol. Cell Biol. 16, 568-576

2. Kuo, J. et al. (2018) Synthetic genome recoding: new genetic codes for new features. Curr. Genet. 64, 327-333

3. Fredens, J. et al. (2019) Total synthesis of Escherichia coli with a recoded genome. Nature 569, 514-518

4. Danchin, A. and Fang, G. (2016) Unknown unknowns: essential genes in quest for function. Microb. Biotechnol. 9, $530-540$

5. Hutchison, C.A. et al. (2016) Design and synthesis of a minimal bacterial genome. Science 351, aad6253

6. Choi, K.R. et al. (2019) Systems metabolic engineering strategies: integrating systems and synthetic biology with metabolic engineering. Trends Biotechnol. Published online February 5, 2019. https://doi.org/10.1016/j. tibtech.2019.2001.2003

7. Nikel, P.I. and de Lorenzo, V. (2018) Pseudomonas putida as a functional chassis for industrial biocatalysis: from native biochemistry to trans-metabolism. Metab. Eng. 50, 142-155

8. Richardson, S.M. et al. (2017) Design of a synthetic yeast genome. Science 355, 1040-1044

9. Calero, P. and Nikel, P.I. (2019) Chasing bacterial chassis for metabolic engineering: a perspective review from classical to non-traditional microorganisms. Microb. Biotechnol. 12, 98-124

10. Breuer, M. et al. (2019) Essential metabolism for a minimal cell. eLife 8, e36842

11. de Lorenzo, V. and Couto, J. (2019) The important versus the exciting: reining contradictions in contemporary biotechnology. Microb. Biotechnol. 12, 32-34

12. Friedrichs, S. et al. (2019) Policy considerations regarding genome editing. Trends Biotechnol. Published online June 19, 2019. https://doi.org/10.1016/.tibtech.2019.2005.2005 